JUAN CARLOS ZULUAGA D. ${ }^{*}$

Universidad de caldas (Manizales, Colombia)

\title{
Afrodescendientes, representaciones y movilidad social en Tuluá ${ }^{* *}$
}

\author{
Afrodescendents people, representations and \\ social mobility at Tuluá
}

\author{
Afrodescendentes, representaçõese \\ mobilidade social em Tuluá
}

\footnotetext{
* Sociólogo, especialista en Políticas Culturales (UB), Magister (c) en Investigación en Ciencias Sociales (UBA). Profesor del departamento de Antropología y Sociología de la Universidad de Caldas. Correo electrónico: juanc.zuluaga@ucaldas.edu.co

** Este artículo de investigación es producto del proyecto Representaciones de movilidad social en migrantes e hijos/nietos de migrantes afrodescendientes del Litoral Pacífico en el municipio de Tuluá-Colombia, desarrollado para optar al título de grado de Maestría en Investigación en Ciencias Sociales de la Universidad de Buenos Aires, Argentina. Artículo recibido el 28/06/2015 y aceptado el 20/07/2015.
} 



\section{Resumen}

Abstract

Resumo

El artículo presenta una síntesis de la investigación sobre representaciones de movilidad social en personas migrantes e hijos de migrantes afrodescendientes en el municipio de Tuluá - Valle del Cauca. Con base en herramientas de análisis cualitativas aplicadas a información recabada sobre un grupo de afrodescendientes residentes en el municipio, el autor analiza algunas manifestaciones discursivas que hablan de representaciones de movilidad social y su relación con la condición étnico racial. Entre los hallazgos se puede resaltar la disonancia entre la percepción positiva y las evidencias de una micromovilidad ascendente de hombres migrantes y sus familias, y la insatisfacción y el no logro o logro parcial de las pretensiones de movilidad tanto de los hijos/nietos de migrantes como de mujeres cabeza de hogar afrodescendientes en la ciudad de Tuluá.

\section{PALABRAS CLAVE:}

Afrodescendientes | movilidad social | representaciones sociales | Tuluá

The article presents a synthesis of research on social mobility representations of migrants and children of migrants of African descent in the town of Tuluá - Valle del Cauca. Based on qualitative analysis tools applied to information gathered about a group of African descent residents in the city, the author analyzes some discursive manifestations that speak of representations of social mobility and its relationship to racial ethnic condition. Among the findings can highlight the dissonance between the positive perception and evidence of an upward micromobility migrant men and their families, and dissatisfaction and no accomplishment or partial accomplishment of the pretensions of mobility of the children / grandchildren of migrants and of women heads of household of African descent in the city of Tuluá.

\section{KEYWORDS:}

African descent | social mobility | social representations | Tuluá

O artigo apresenta uma síntese da pesquisa sobre representações de mobilidade social em pessoas migrantes e filhos de migrantes afrodescendentes no município de Tuluá -Valle del Cauca. Com base em ferramentas de análise qualitativas aplicadas à informação coletada 
sobre um grupo de afrodescendentes residentes no município, o autor analisa algumas manifestações discursivas que falam de representações de mobilidade social e sua relação com a condição étnico racial. Entre os descobrimentos pode-se destacar a dissonância entre a percepção positiva e as evidências de micro mobilidade ascendente de homens migrantes e suas famílias, e a insatisfação e a não conquista ou conquista parcial das pretensões de mobilidade tanto dos filhos/netos de migrantes como de mulheres chefes de família-mães solteiras- afrodescendentes na cidade de Tuluá.

PALAVRAS - CHAVE:

Afrodescendentes | mobilidade social | representações sociais | Tuluá 


\section{Introducción}

El proceso de industrialización en la producción de caña de azúcar a mediados del siglo XX significó un cambio trascendental en la vida social y económica, y en el paisaje natural y cultural del valle geográfico del río Cauca. Además de estimular procesos migratorios trajo consigo la presión sobre la pequeña y mediana propiedad por parte de los terratenientes (Bravo, et al., 2002). La industria azucarera en su expansión concentra tierras y sirve eficazmente al proceso de descampesinización de las comunidades agrícolas, ubicándolas en la lógica del proceso de proletarización como jornaleros, trabajadores asalariados o por contrato, causando un fuerte impacto en la economía campesina y en las condiciones socioculturales de los grupos afrodescendientes ${ }^{1}$ migrantes u oriundos de la región (Cifuentes, 1986).

Dicho sector industrial en el Valle del Cauca ha vinculado históricamente una gran masa de población afrodescendiente en todas sus zonas de influencia, constituyendo focos de asentamiento de estas comunidades en municipios tales como Candelaria, Florida, Timba, Palmira, Cerrito, Guacarí, La Paila, Zarzal y Tuluá entre otros. La expansión de estos municipios, luego del despegue de la agroindustria de la caña, se da gracias a la migración de una gran cantidad de personas del Litoral Pacífico, primordialmente hombres, hacia Cali y los poblados contiguos a los ingenios azucareros, como en el caso de Tuluá, donde se enganchan como corteros. Según Taussig (1979), para esta época migran muchos más hombres que mujeres, y cuando estas lo hacen es para vincularse como jornaleras o como empleadas domésticas. Tanto el migrante cortero como la trabajadora rural y la migrante empleada doméstica viven una vida muy distante de lo que sería en sus pueblos: aislados, sometidos a la rutina, encerrados bien sea en la casa o en la plantación y con un solo día libre. Esas nuevas plantaciones de caña están organizadas dentro de un sistema vertical de control y vigilancia, algo a lo que no están acostumbrados las personas negras en los ríos o quebradas en las que se desenvuelve su cotidianidad.

En la década del 50 los propios ingenios promueven la migración de personas del litoral a través de lo que se conoció como el "enganche" de trabajadores. El ingenio enviaba a un representante, generalmente un trabajador de la región, para que enganchara trabajadores de poblaciones del Pacífico (Guapi, Saija, Timbiquí, Lopez de Micay). Ya en 1964 las migraciones estaban tan generalizadas que no era necesario hacer reclutamiento de personal a través del enganche. De hecho, había exceso de mano de obra (Knight, 1986). Las comunidades del Pacífico, constreñidas por la pobreza estructural y atraídas por los discursos urbanos que hablaban de desarrollo y mejores condiciones de vida, se vieron impelidas a emigrar y poblar territorios suburbanos, ocupando un lugar de ciudadano

1. En este artículo se hace uso de téminos afro, afrodescendientes y personas negras y mulatas, como equivalentes, aun cuando se reconocen diferencias entre los mismos según las formas históricas de denominación y las posiciones político-identitarias de quienes optan por uno u otro de estos términos. Así, siguiendo a Barbary y Urrea (2004: 52), con estas denominaciones nos referimos a "las poblaciones que de algún modo son descendientes, a través de múltiples generaciones y dinámicas de mestizaje, de los antiguos esclavos africanos”. 
de segunda categoría ${ }^{2}$; en el caso del emigrante del Pacífico le acompañaban elementos de clase, etnia y región que le harían sufrir de una triple discriminación.

Para las mujeres se sumarían a los anteriores rasgos susceptibles de discriminación la condición de género, lo cual la llevaría a ocupar el menor rango en la estructura del empleo, es decir que se vería generalmente abocada al trabajo doméstico, empleos rurales mal pagos o al mercado informal, principalmente como vendedora de productos agrícolas o dulces propios de su región.

Señala Taussig (1979) que para el año 1975, el setenta por ciento de los corteros estaba empleado directamente por el ingenio y el treinta por ciento estaba empleado por contratistas independientes. Desde la década del 90 estas proporciones se han invertido radicalmente. Según datos de Asocaña, para el 2008 el setenta y ocho por ciento de los corteros estaba vinculado a través de contratistas, y hoy esta proporción se ha incrementado a través de la figura de empresas de cosech a o corte. ${ }^{3}$ La situación de los corteros se visibiliza en distintas protestas y huelgas en el último cuarto del siglo XX. Sin embargo, el cese de actividades realizado por más de doce mil corteros en el mes de septiembre de 2008 es el que ha generado mayor impacto no sólo mediático sino económico, social y político en la región y el país. Por más que el gobierno nacional y los medios de comunicación de mayor influencia se empeñaran en tomar partido a favor del gran capital manipulando la opinión pública, la resistencia de los corteros puso de manifiesto la situación de quienes no cuentan con las mínimas condiciones de justicia social.

Durante las últimas dos décadas, factores ligados principalmente al conflicto armado, y a la lucha por el control del territorio por parte de grupos ilegales, las poblaciones del Pacífico siguen presentando altos índices de desplazamiento forzado, especialmente en la zona centro-sur del litoral, aun cuando las personas migrantes entrevistadas tuvieron sus procesos migratorios en décadas anteriores y sus motivos de desplazamiento no tuvieron que ver con el conflicto armado.

Según lo muestran los estudios (Hurtado, 1996; Vanin, 1998; Urrea y Murillo, 1999; Urrea, et al., 2000; Jaramillo, 2003), generalmente las personas migrantes se instalan en primera instancia en las cabeceras municipales o en ciudades intermedias, donde se

\footnotetext{
2. Si bien las personas migrantes que colaboraron con el estudio inician sus procesos migratorios hacia la segunda mitad del siglo XX con un bajo capital económico y escolar, cabe destacar que ya para la época, y desde mediados del siglo XIX en algunas regiones del caribe, una minoría de personas negro-mulatas con cierto capital económico y cultural acumulado hacían parte de las clases medias en ciudades como Cartagena, Bogotá y Cali, aun cuando no siempre se identificaran con estos sectores sino con las sectores populares, como es el caso de los activistas del Club Negro y el Centro de Estudios Afrocolombianos, quienes reclamaban a aquellos que ascendiendo socialmente se alejaban de su grupo de origen y de los valores de la población afro (Pisano, 2011).

3. Por la presión y movilización de los corteros de caña las Cooperativas de Trabajo Asociado (CTA) son reemplazadas hacia el año 2012 por las llamadas Empresas de Cosecha o de Corte. Sin embargo, estas últimas constituyen una estrategia del oligopolio azucarero para mantener y extender la tercerización del empleo en el sector, desafectando a los ingenios de responsabilidades laborales y fiscales para con los corteros de caña.
} 
radican u optan por el retorno o dar el salto a los grandes centros urbanos como Bogotá, Cali, Medellín u otras ciudades del país y del exterior. De otra parte, muestran que los procesos migratorios y de desplazamiento, además de tener un impacto directo en las dinámicas de la ciudad, afectan de manera particular y diferenciada la vida de la persona y del grupo migrante o desplazado, conllevando muchas veces la pérdida del tejido social, así como la marginación, segregación y discriminación en los territorios de llegada, donde a pesar del aporte productivo que hacen al conjunto de la sociedad se mantienen en condiciones de desigualdad, precariedad económica y desventaja cultural.

Algunos autores como Urrea (2010), Viáfara, et al. (2010), han desarrollado investigaciones que muestran, el primero las condiciones de vida desfavorables de la población afro con respecto al conjunto de la población de la ciudad de Cali y la región norte del departamento del Cauca, y los segundos los diferenciales de movilidad entre afros y no afros en los estratos 1, 2 y 3 en la ciudad de Bogotá y trece áreas metropolitanas del país, señalando mayores situaciones de inmovilidad de la población afro frente a los no afro. Sin embargo, son pocos los estudios dedicados exclusivamente a la movilidad social de la población negra migrante en el país.

La finalidad de la investigación, de la cual se presenta aquí una síntesis, no se centró en esclarecer la naturaleza del bienestar o la movilidad social, sino en identificar comparativamente las dimensiones y los elementos centrales de las representaciones de movilidad social de aquellos migrantes afro de los años 50-70 y sus descendientes en el municipio de Tuluá, analizando las relaciones entre estas representaciones y los factores objetivos que facilitan o dificultan dicho proceso de movilidad.

En líneas generales, en el estudio se identificaron los elementos centrales y periféricos de la representación de movilidad y las valoraciones que de ellos hacen las personas migrantes e hijos de migrantes afrodescendientes en el municipio de Tuluá. Así, el trabajo, la educación y la salud emergen como las principales factores que sirven de base a las imágenes de ascenso social, pues son ellas en sí mismas manifestaciones, históricamente constituidas, del estatus de las personas, o los medios a través de los cuales las personas conciben la posibilidad de alcanzar logros sociales y materiales.

\section{Aspectos metodológicos del estudio}

El diseño metodológico de la investigación partió de la base de datos construida en un estudio previo, intitulado: "Caracterización sociodemográfica, socioeconómica y sociocultural de la población afrodescendiente en Tuluá, Valle del Cauca". ${ }^{4}$ En esta base de datos se encuentra información de índole cualitativa y cuantitativa de doscientos 
hogares afrodescendientes residenciados en el municipio, la cual se construyó a partir de doscientas encuestas y un conjunto de 16 entrevistas con personas cabeza de familia. Cabe anotar que la ciudad de Tuluá en la actualidad cuenta con una presencia considerable de población afrodescendiente en, al menos, 15 barrios del municipio y en la zona rural, que según datos del DANE (2005) es de 15347 personas sobre un total de 148550 habitantes del municipio (10,3\% de la población total), de las cuales la inmensa mayoría corresponde a estratos bajos y medios bajos (1, 2 y 3$)$.

De acuerdo con los resultados de la caracterización de esta población se definieron los criterios de selección de personas para la pesquisa. ${ }^{5}$ Según estos criterios de selección se contactaron las personas que colaboraron con el estudio: personas migrantes de primera generación; personas hijo(a)s de migrantes y nieto(a)s de migrantes. Dadas las características y los objetivos del estudio se desarrolló un enfoque de investigación cualitativa donde la unidad de análisis fueron las representaciones de movilidad social en las personas entrevistadas. Si bien los criterios de selección no pretenden generalizar sobre la población afrodescendiente residente en Tuluá, ni tampoco cerrar los criterios de clasificación, sí se buscó cierta representatividad al identificar hogares tipo y posibles colaboradores con características socioeconómicas y demográficas definidas censalmente, que permitieran un acercamiento en la construcción de la realidad social de este grupo poblacional.

Se realizaron doce (12) entrevistas individuales y dos grupales en un arco temporal que cubrió desde agosto hasta octubre de 2013. Las entrevistas se coordinaron y agendaron previamente con los informantes, en cuanto a días y horas de los encuentros. Así, el recaudo de información se realizó en cuatro momentos temporalmente consecutivos: 1. Entre 12 y 14 de agosto. 2. Los días 13 y 14 de septiembre. 3. Entre el 21 y 23 de septiembre. 4. Los días 4 y 5 de octubre. Las entrevistas en grupo siguieron la técnica de los grupos focales, los cuales fueron definidos a partir de la condición etaria de los individuos (jóvenes y adultos) y moderados por el investigador a partir de una guía temática.

El análisis de la información se realizó siguiendo los parámetros de la teoría fundamentada: el recaudo de información y el análisis se desarrollaron de manera paralela donde las primeras entrevistas dieron lugar a conceptualizaciones iniciales, que conforme se avanzó en la pesquisa fueron refinadas y delimitadas (muestreo teórico) hasta considerar que se llegó a la denominada saturación teórica. La indagación buscó establecer no solo los significados sino también la estructura y jerarquía de las representaciones de movilidad social, en el marco de la teoría del núcleo central (Abric, 2001). Según el autor, la representación social es constituida por un(os) código(s) centrale(s) (nucleo central) y unos elementos periféricos. El código central es el elemento principal porque determina el significado de la representación como un todo, pero también determina su estructura. Además, "el núcleo central de representación es estable, coherente, ex- 
presa consenso y está considerablemente influido por la memoria colectiva del grupo y su sistema de valores" (Abric, 2001: 23).

Si bien seguimos los presupuestos teóricos de la teoría del núcleo central, no hacemos lo mismo en cuanto a su proceder metodológico, pues Abric y la escuela de Aix -Provence- acude a herramientas tales como los denominados tris jerarquizados, las asociaciones libres y las encuestas para explorar tanto los significados como las jerarquías de los elementos. En nuestro caso, y siguiendo a Rodríguez (2007), consideramos que las técnicas cualitativas pueden dar respuesta, incluso un mejor acercamiento, a los problemas planteados al estudio de las estructuras cognitivas de los sujetos en relación con el contexto y los valores sociales. Así, aplicando una metodología discursiva como la entrevista pretendimos acercarnos a la estructura significativa de movilidad social que producen y reproducen tanto los migrantes afrodescendientes como sus hijo(a)s/ nieto(a)s en el municipio de Tuluá.

\section{¿Qué significa ascender socialmente?}

Las personas entrevistadas que hacen parte de la población migrante del Pacífico colombiano en el municipio de Tuluá, enuncian con mayor frecuencia el ascenso social como un "mejor estar" o una "mejor vida", mientras que la siguiente generación, aquellas personas que migraron junto a sus padres siendo niños o que nacieron en el municipio, se refieren al ascenso social en términos de "salir adelante". Es claro que la pareja conceptual ascenso/descenso constituye el marco lógico sobre el que se define la movilidad social en ciencias sociales, medida ésta a partir de los cambios, intra o intergeneracionales, en el nivel de educación, de la ocupación, de los ingresos o la riqueza y de los niveles socioeconómicos, lo que para las personas entrevistadas se estructura a partir de las parejas mejor/peor, adelante/atrás. En tal sentido, el ascenso social es percibido por los informantes como un proceso vinculado con el paso de unas difíciles condiciones de vida a unas más y mejor valoradas, objetivadas éstas en logros sociales, culturales y económicos. Sobre los ámbitos y los elementos que constituyen el mejor estar, la mejor vida y el salir adelante se centró buena parte del estudio.

Investigaciones sobre bienestar subjetivo han mostrado que el sentirse bien es parte importante del estar bien (Diener, 1994; Veenhoven, 1994), así como el sentirse mejor resulta fundamental del mejor estar. En términos de percepciones, el "sentirse bien" y el "sentirse mejor" son referentes positivos del bienestar subjetivo y la movilidad subjetiva, respectivamente. Según lo muestra la pesquisa el ascenso social, el mejor estar, el sentirse mejor, es representado por las personas como una aspiración, que no sólo se da para el grupo en cuestión, pues según Veblen (1974) los seres humanos siempre aspiramos a incrementar nuestra autoestimación, la cual se basa en gran parte 
en la estimación social, dada ésta en buena medida por la posición que ocupemos o lleguemos a ocupar en la estructura social. Para los migrantes del Pacífico en Tuluá y sus descendientes, alcanzar un mejor estar, una mejor vida o salir adelante, depende indudablemente de condiciones objetivas, relacionadas principalmente con oportunidades de estudio (para sus hijos), trabajo y los recursos económicos y consumos que de él derivan, las cuales a su vez son orientadas sobre una base moral de principios y valores, que no sólo ejercen influencia en las prácticas sino también en el sentido y la percepción de la propia movilidad social de los sujetos.

Es importante señalar que las tres nociones guardan estrecha relación, en la medida que denotan un sentido positivo del cambio (mejorar, ir adelante), siendo conceptos emergentes de los datos que se vinculan significativamente con la noción de bienestar, pero no son asimilables a la misma, dado que estar bien (vivir bien o sentirse bien) no viene a ser lo mismo que estar mejor (vivir mejor o sentirse mejor), pues éste último induce a pensar en cierto proceso de evaluación dinámica, no sólo del presente (el estar bien en un momento determinado), sino también del futuro. Incluye pues una mirada prospectiva convertida en aspiración a unas mejores condiciones de vida, visualizadas éstas a partir de las situaciones pasadas, individuales y colectivas. Así, mejor estar, mejor vida o salir adelante, hablan de un cambio cuantitativo y cualitativo, una transformación en el tiempo, así como de una evaluación en las condiciones de existencia anteriores y actualmente vividas por los propios informantes y por sus familias de origen. Sin embargo, entre los dos primeros términos y el tercero se hallan diferencias en lo que refiere a los elementos que constituyen la representación de ese cambio y la valoración jerárquica que se hace de los mismos, lo cual influye en la percepción de movilidad social según sea vista desde la perspectiva de los primeros migrantes o desde la de sus descendientes.

\section{Mejor estar: explotación, esfuerzo y micromovilidad ascendente}

En las siguientes declaraciones se muestra como la aspiración a unas mejores condiciones de vida, a un mejor estar, constituye el principal motivo que tuvieron para salir de sus territorios de origen y luego residenciarse en el municipio de Tuluá los migrantes afrodescendientes entrevistados:

Yo me vine en el cincuenta y tres, fui en el cincuenta y cinco y así... y así, para una parte y otra buscando un mejor estar (Juan, septiembre 23/2013)

Cuando nos vinimos de Guapi, pues era para ver si acá nos iba mejor que allá. (Arcadia, septiembre 14/2013) 
En la tierra de nosotros hay muchas necesidades, mucha pobreza, toca muy duro para conseguirse cualquier pesito. Por eso... no sólo yo, sino que muchos vinimos a buscarnos una mejor vida por acá (Medardo, agosto 14/2013)

Sin desconocer otras causas de la migración, como son las motivaciones de índole personal y las asociadas al fenómeno de desplazamiento forzado (a partir de los años 90 del siglo pasado), para el caso de los migrantes entrevistados la aspiración a un mejor estar implicó la exploración, la búsqueda de un entorno favorable para cumplir con sus propias aspiraciones de una mejor vida. Es necesario considerar que la motivación de estos migrantes (años 50-70) parte de las precariedades económicas de la época y las pocas oportunidades de empleo, cuando apenas se daba un incipiente intercambio monetario en la mayoría de los territorios del Pacífico.

Para la segunda mitad del siglo veinte, en la medida que la región del Pacífico tuvo un mayor contacto (material y simbólico) con los procesos de modernización del estado-nación, también han sido resignificados y/o transformados los ideales, las prácticas y los consumos tradicionales, configurando condiciones que coadyuvan a multiplicar los flujos migratorios. Los ideales y las prácticas económicas tradicionales entran en crisis, en parte cuando el dinero se convierte en 'necesidad' y empieza a imponerse como forma de intercambio material, haciéndose indispensable para el consumo de los servicios, bienes y mercancías incorporados desde el interior del país a una economía local y hasta cierto punto cerrada por las dificultades para la comercialización de los productos de la región. Esto configura un escenario en el que el dinero es un bien apreciado, pero escaso y de poca circulación. En palabras de los migrantes a Tuluá:

Allá todos cultivamos, cosechamos maízy el que no cosecha, puederozar, va a coger maiz, hay que darle parte, participación. Y entonces todos tenemos cosechas y no hay a quien venderle. Si yo tengo una platanera...bueno, una platanera puede ser lo mejor que haiga. $Y$, ¿a quien le vende?... Cuando usted no tiene, yo le digo: don fulano camine, vamos pa la finca a traer plátanos. Y usted va a cargar plátanosy usted saca de allá de la finca cuatro racimos de plátano, son dos suyosy dos mios... Asi es allá. ${ }^{6}$ (Medardo, agosto 14/2013)

Mipapá cultivaba el plátanoy el maíz [en Novita-Chocó], pero era mi mamála quelo tenía que cogery distribuirlo al hombro de nosotros [los hijos]...cargándolo como de Tuluáa Andalucía al hombro [10 km. Aprox.]. Era un trabajo muy duro porque no habia ni siquiera bestia para transportarlos, los caminos son muy dificilesy no hay carretera (Adelina, septiembre 23/3013)

En la actualidad, y desde hace unas décadas, se tiene conocimiento y se reconocen, por lo menos en el ámbito académico, las desigualdades históricas y las distintas formas 
de opresión y marginalidad operada sobre las comunidades étnicas en nuestro territorio, y muy especialmente sobre la población afrodescendiente, identificada con los índices más altos de pobreza y marginalidad.7 La población de las zonas rurales del Pacífico colombiano, con una inmensa mayoría de personas afro (80 \%), no sólo cuenta con suficientes obstáculos para la producción sino también para la comercialización de los productos, dado el aislamiento y la poca infraestructura en vías de comunicación, lo cual no sólo dificulta sino que encarece los costos en el transporte derivando en una pírrica o ninguna ganancia económica para las familias en dichas zonas. Indefectiblemente un mejor estar requiere, entre otras cosas, de contar con una mayor cantidad de recursos económicos, representados en dinero, un bien escaso en dichos territorios, mucho más para los años cincuenta y sesenta cuando se dan las primeras migraciones a gran escala hacia el interior del país. En medio de la carencia, el migrante aspiraba a una vida con menos afugias y dificultades, con cierta tranquilidad económica que le facilitara satisfacer sus necesidades básicas:

Yo buscaba un mejor estar: estar un poco tranquilo, que se viera la plata, porque la plata en el tiempo de nosotros se veía muy poco...un mejor estar tranquilo, y si, una mejor vida (Juan, septiembre 23/2013)

Demitierra recuerdo que amasaba maiz, rozaba arroz, así, cosas del monte. Me dedicaba pues a trabajar, tener unos trabajitos así, pero se veía poca plata (Arcadia, septiembre 14/2013)

Como se describió en páginas anteriores, las condiciones estructurales del país referidas a la expansión de la industria azucarera (años 1950-60), principalmente en el valle geográfico del río Cauca, incentivaron los primeros procesos migratorios a gran escala desde el Pacífico Sur colombiano, constituyendo un medio para miembros de las comunidades, principalmente hombres, de incorporarse a la sociedad del interior del país, así como una oportunidad para la industria de obtener mano de obra barata y capacitada para las arduas labores del campo y con unos principios éticos y morales adquiridos en el contexto socio-cultural de origen, principalmente en lo que es y significa el trabajo.

Para el caso de las personas que hacen parte del grupo de migrantes afrodescendientes entrevistados el trabajo se percibe, después de la familia, como la principal institución y el elemento más importante de incorporación de los individuos a la vida social, considerándose como una insitución en la que se inscriben los cuerpos de las personas mucho

7. Según los autores: "de acuerdo con el primer criterio -la línea de pobreza-, la proporción de pobres e indigentes dentro de la población negra es claramente más alta que la de la población mestiza, tanto en las zonas rurales como en las urbanas. El nivel de pobreza de la gente negra en Colombia es muy alto [...] Más del 60\% de los afrocolombianos son pobres y, en las zonas rurales, lo son casi las dos terceras partes de ellos. Aún más grave es el hecho de que casi la quinta parte de los afrocolombianos vive en la miseria, esto es, no tiene ingresos ni siquiera para comprar los alimentos de una dieta mínima” (Rodríguez, et al., 2008: 31). 
antes que en otras como la educación formal. Puede decirse que las personas migrantes del litoral pacífico a Tuluá fueron formadas en una "ética del trabajo" que se percibe como parte de una identidad étnico-regional. Esta ética está configurada a partir de preceptos morales y sociales relacionados con el trabajo: el sentido obligatorio y de colaboración, la responsabilidad y la honradez (el trabajo honrado); también incluye elementos asociados a la formación del carácter y la personalidad como son el esfuerzo y la tenacidad; y una serie de saberes prácticos relacionados con las labores domésticas y oficios del campo aprendidos desde muy corta edad y diferenciados según el género.

No obstante el representar para los migrantes unas mejores condiciones económicas a las anteriormente vividas, la incorporación a los nuevos territorios se materializa ubicándolos en los últimos peldaños en la escala ocupacional y de prestigio: los hombres en trabajos rurales, el mayor de los casos como "corteros" de caña, oficio asignado casi exclusivamente a los afrodescendientes; y las mujeres en oficios domésticos o en labores del campo, las cuales eran bastante ofertadas para la época en los alrededores del entonces pequeño casco urbano de Tuluá, cuando aún no se había consolidado el monocultivo de la caña de azúcar.

Sin pasar por alto el grado de explotación laboral al que son sometidas las personas negras, se entiende que para los migrantes la noción de ascenso social está relacionada con una mayor obtención de recursos a través de un buen número de oportunidades laborales en el sector rural de Tuluá, a las que se vinculaba todo el grupo familiar, ejerciendo tareas para las cuales se encontraban equipados con un conjunto naturalizado de ideas, preceptos y consideraciones en torno a lo que es y significa el trabajo, además de una serie de competencias y prácticas propias de las labores del campo (Zuluaga, 200o). Para esta generación de migrantes se abrieron las puertas en estos oficios, pero solo en ellos, pues cualquier aspiración a trabajos más cualificados y mejor calificados era en esa época casi completamente impensable ${ }^{8}$, y aún hoy difícil de lograr para las personas negras, pues las dificultades que ellos afrontaron, y que aún afrontan sus descendientes para lograr un ascenso social (discriminación racial, cierre de oportunidades, poca cualificación), constituyen taras para tales propósitos no sólo en el municipio de Tuluá sino en casi la totalidad del territorio nacional.

Históricamente se condenó en nuestro territorio a los afrodescendientes a los trabajos más difíciles así como a los estatus más bajos de la sociedad, configurando unos esquemas culturales convertidos en estereotipos que justificarán y servirán de soporte a las desigualdades (Wade, 1997). Algunos de estos estereotipos están constituidos y contenidos en discursos que predican la predisposición biológica (racial) de las personas

8. Situación similar encuentra Viáfara (2006) en la ciudad de Cali. Mostrando resultados econométricos el autor concluye que hasta 1972 el mercado laboral en dicha ciudad presenta para las personas negras bajas probalidades de acceso a ocupaciones no manuales y manuales de alta calificación, pero mayores probabilidades de ingresar a ocupaciones manuales no calificadas. 
afrodescendientes al trabajo pesado y bajo difíciles condiciones, lo cual coadyuva a predeterminar social y simbólicamente para esta población los segmentos ocupacionales de mayor exigencia física pero de menor estatus en la escala de prestigio.

No obstante las disposiciones racializadas en la estructura del empleo, las opiniones de las personas migrantes entrevistadas, especialmente los hombres, consideran positivamente tal discriminación en la medida que les significó un reconocimiento social que pudo repercutir en mayores oportunidades de empleo y mejor estima en el mercado laboral en el cual pretendían competir (rural). De tal forma, podría decirse que la discriminación racial y la estigmatización operada en una actividad como el trabajo resultó instrumentalizada por las personas en situación de desigualdad, en este caso por la población negra migrante, haciendo de dicha discriminación un elemento que favorecía sus aspiraciones, dado que les confería cierta superioridad a los hombres afro frente a blancos y mestizos en el ámbito de la lucha por oportunidades laborales en el sector rural, especialmente en el corte de caña:

\section{A losmestizos losingeniosno los recibían porque eran malos para el sol, se quemaban. Entonces ellos se iban era a coger caféy a nosotros nos ponían en primera fila [en los ingenios] (Medardo, agosto 14/2013)}

Para los trabajos eso le vían a uno la cara y todo eso, pero yo, allá donde fui a trabajar [hacienda], yo limpiaba sequia, de todo así, mojaba esos potreros. Allá, mire que cuando yo fui allá, venía un tipo, un mestizo, y se demoraba siete días mojando esospotreros, y yo los mojaba en una noche. Todos esos siete potreros los mojaba en una noche (Fabio, septiembre 13/2013)

Ya a los negros empezaron a reconocernos por el trabajo, porque ya por lo menos había mucha gente queya no aguantaba para el sol,y muchos decían: ahhh ese sol es como para negros [risas], que el corte de caña es para los negros (Juan, septiembre 23/2013)

El acervo cultural y las competencias de los migrantes en las labores del campo, así como los condicionamientos de la estructura social y ocupacional racializada establecen un marco a la dinámica, el sentido y la significación de la movilidad y el ascenso social para los migrantes afrodescendientes, restringiendo dicha movilidad en lo que para Elster (1996) serían los límites en la relación entre oportunidades y deseos: aquello que me es inalcanzable, que está por fuera del marco de mis oportunidades, no hará parte del conjunto de mis deseos o aspiraciones. De tal forma, el significado de ascenso social que elabora la población migrante entrevistada parte de lo que hemos llamado una micromovilidad social ${ }^{9}$, un proceso lento y pausado cargado de esfuerzo y disciplina, 
suficiente para dar muestra de una mejora, a veces sustancial, a veces no tanto, en las condiciones de vida, pero nunca un verdadero ascenso social.

\section{Las empresas dicen ascender cuando uno es... cuando uno está en un cargo y lo suben a otro} cargo: ascendió, ¿ya? Pero no sólo eso es ascender, sino que si uno está en una situación bajay va subiendo, va subiendo...entonces va ascendiendo (Medardo, septiembre 21/2013)

El anterior comentario resulta paradigmático en cuanto a la percepción de movilidad social en los migrantes, estableciendo un parangón entre la noción de ascenso social y el ascenso laboral, asimilando pero a la vez diferenciando ésta última a la de la esfera socioeconómica, considerando la particularidad de que dicho ascenso no se da de una manera drástica o de un momento a otro, como sucede cuando a la persona se le asciende de cargo en la empresa, sino que se trata de todo un proceso en el cual la persona va mejorando, poco a poco, sus condiciones de vida, siguiendo cada vez su aspiración a un "mejor estar".

$\mathrm{El}$ "mejor estar" es percibido por los entrevistados como una aspiración y también como un proceso que depende en buena medida de que las condiciones objetivas muestren o indiquen una mejora de las mismas, en el caso anterior asemejado simbólicamente por el entrevistado con un nombramiento en un puesto de mayor nivel en la escala ocupacional y de prestigio, cosa difícil de obtener para un cortero de caña en un ingenio azucarero cualquiera, pues salvo que se participe en la organización sindical éstos tienen muy pocas posibilidades de alcanzar cargos administrativos, manteniéndose por regla general en el corte de caña como peones u oficiales durante toda su vida laboral. Ascender en el ámbito jerárquico empresarial u ocupacional no es la forma esperada de ascenso social en el imaginario de los migrantes, orientándose éste a pequeñas mejoras en las condiciones de vida y en logros paulatinos (micromovilidad) como la obtención de un lote o de una casa propia construida por etapas, o de un mejor nivel educativo (principalmente para los hijos), los cuales requieren de una mentalidad instrumental y prospectiva (orientada al ahorro), de un esfuerzo personal y

una mínima probabilidad de que se logre un verdadero ascenso social siguiendo los criterios normativos culturales y legales, señalando un par de casos específicos de personas afrodescendientes en Tuluá, se presenta en ellos la idea generalizada de que es muy difícil, casi imposible, que éste se haga realidad para las personas negras, aunque no solo para ellas, siguiendo el marco normativo. El análisis de las entrevistas muestra que en el imaginario de los informantes no es el trabajo legalmente constituido el medio más probable de ascenso social y acumulación de recursos económicos sino, por el contrario, desacatando los criterios normativos y trasegando la ilegalidad. Así, para los entrevistados, quienes orientan su acción desde la adscripción a un valor como la honradez, constituye este mismo valor una frontera simbólica en las posibilidades de ascenso social, en la medida que consideran muy difícil de lograrlo siguiendo el precepto ético, configurando para el grupo en cuestión una percepción de alta inmovilidad en la estructura social, tan solo quebrantada en casos específicos y en situaciones de ilegalidad, aunque a nivel micro se mantienen las aspiraciones de lograr unas mejores condiciones de vida (micromovilidad) a través del estrecho marco de oportunidades que se les presenta. 
del acogerse a unos principios éticos ${ }^{10}$, tanto como de las oportunidades simbólicas y materiales ofrecidas por el contexto social.

El estudio muestra una micromovilidad ascendente y una percepción positiva de movilidad social entre los hombres migrantes entrevistados y sus familias, llenando sus expectativas en cuanto a logros sociales (mínimo reconocimiento), económicos (vivienda) y culturales (nivel educativo de los hijos) ${ }^{11}$, gracias principalmente al esfuerzo personal y familiar, a las condiciones de contratación directa con los mínimos derechos y prestaciones sociales (por regla general en los ingenios), así como a la unión y la potencia solidaria de los sindicatos y las cooperativas, las cuales fueron bastiones en esos procesos.

La situación de las mujeres cabeza de hogar puede considerarse la más crítica, pues en sus trayectorias biográficas no tuvieron acceso a la educación ni a condiciones laborales formales y estables, desarrollando actividades productivas en ocupaciones no calificadas y mal remuneradas. Es así como no cuentan en la actualidad con vivienda propia, ni la ayuda económica de una pensión, configurando en ellas más que en las otras personas entrevistadas una percepción de malestar, insatisfacción con la vida y representaciones negativas de su propia movilidad social. Es claro que sobre las mujeres afro recae además de la discriminación racial y de clase, la mentalidad y las prácticas patriarcales que suponen una inferioridad (física, mental, simbólica, política) de las mujeres frente a los hombres, asignándoles material y simbólicamente oficios y roles tradicionalmente relacionados con el espacio doméstico. ${ }^{12}$

Situaciones similares se presentan para las hijos/nietos de los migrantes, para quienes las transformaciones en la estructura del empleo y las condiciones históricas de desigualdad y discriminación racial reducen el campo de oportunidades, llevándolos a la precariedad e induciéndoles a vivir bajo una lógica existencial.

Asimismo son los jóvenes y las personas de mediana edad quienes en mayor medida expresan y reconocen los vínculos entre el cierre de oportunidades (laborales, educativas, financieras y políticas) y la discriminación racial. En este sentido, se identificó en el estudio la transversalidad del elemento racial en las evaluaciones que hacen los

10. Por cuestiones de espacio en el artículo no se desarrollan estos aspectos, los cuales fueron identificados en el estudio como parte del marco ético, lógico y práctico de las representaciones de movilidad social.

11. El logro de los migrantes en la adquisición de vivienda lo demuestra el hecho que con el proceso migratorio se da el asentamiento acelerado de población negra migrante hacia el noroccidente de la ciudad de Tuluá, constituyendo una veintena de barrios en el municipio. De otro lado, los mejores niveles educativos de las personas jóvenes y de mediana edad entrevistadas, respecto a los de sus antecesores, dan cuenta del cumplimiento de las expectativas de los migrantes en el ámbito de la educación de los hijos, generalmente haciéndolos bachilleres, aún cuando este logro resulte insuficiente para el ascenso social de las nuevas generaciones.

12. Al tiempo que se establecen las jerarquías raciales en el ámbito de la producción, se reproduce el orden patriarcal que pone en condiciones de inferioridad a las mujeres frente a los hombres, lo cual se materializa en relaciones asimétricas entre unos grupos y otros, y donde la mujer afro, por su doble condición (mujer-afro), se pone en situación de vulnerabilidad y resulta mucho más susceptible de ser víctima de discriminación. 
intrevistados de los obstáculos para el ascenso social, con algunas variaciones entre cohortes generacionales, considerándose en ocasiones de manera aislada y en otras percibido como parte de un sistema de clasificación y descalificación de las personas negras, así como de sus producciones materiales y simbólicas.

\section{Salir adelante: un proyecto de vida cegado en oportunidades}

Si el mejor estar o la mejor vida constituye un patrón significativo de la movilidad social ascendente para los migrantes, para los hijos de estos el salir adelante constituye la aspiración central. Ambas nociones apuntan a una mejora en las condiciones materiales de vida utilizando como medio fundamental el trabajo, pero a diferencia de los primeros el salir adelante se orienta, para las nuevas generaciones, en la posibilidad de obtener empleos distintos y mejor remunerados a los de sus padres, necesitando para ello superar sus niveles educativos, adquiriendo un tipo de conocimientos, actitudes y prácticas con las cuales puedan competir en otros ámbitos del mercado laboral, lo que podría entenderse desde la perspectiva de Bourdieu (1990) como una necesidad de inversión en capital cultural. De tal forma que el ascenso social se vislumbra en las nuevas generaciones a partir de la materialización de logros en ese sentido:

Mi expectativa es salir adelante, tenermiproyecto devida, ser una profesional, que en cualquier parte que yo vaya pues tenga un trabajo (Adriana, octubre 04/2013)

Desde la casa siempre mi papá decía que si uno quería salir adelante y buscar una buena posición en una empresa o donde se fuera, tenía que tener unos grados de educación para poder ocupar esos espacios (Hoover, agosto 13/2013)

Una persona ha salido adelante cuando haiga estudiado, que consiga un trabajo en una buena empresa, que gane buena plata.. Bueno, salió adelante. Porque de pronto se hizo a su casa, a sus cosas y no está pasando tantas necesidades como uno (Patricia, octubre $04 / 2013$ )

La valoración positiva de la educación se inscribe en las nuevas generaciones a partir de los valores del contexto social, donde la educación se concibe como la opción más legítima en el camino del éxito; y del contexto familiar, pues si bien ninguna de las personas migrantes entrevistadas superó el nivel de básica primaria, entre sus mayores expectativas se encontraba la de proveer, en la medida de lo posible, estudio para sus hijos, incluyéndolo en sus imaginarios de movilidad como elemento central, ya no para sí mismos sino para sus descendientes.

Este interés de los padres por la educación de sus hijos está mediado por la adecuación de sus propósitos y aspiraciones al orden de las valoraciones sociales dadas en el lugar de llegada, en este caso la sociedad tulueña. Así, lo que quizás no constituía para 
la época prerrequisito cultural y social (la educación formal) en sus comunidades de origen, donde la institucionalidad educativa apenas operaba o no existía, pasa a convertirse en algo altamente valorado entre las competencias deseadas para los hijos en el contexto de llegada.

El anhelo de profesionalizar y de mejorar el estatus ocupacional de los hijos son aspiraciones legítimas que toman forma de representación social de movilidad, no solo para la población afrodescendiente sino para casi todos los grupos sociales, si bien algunos estudios de movilidad social en Colombia (Grillo y Nina; 2000) muestran que el $30 \%$ más pobre de la población (estratos 1,2 y 3 ) tiene un alto grado de inmovilidad, así como una alta probabilidad de no cambiar el nivel de educación de sus padres. Según estos autores la baja movilidad social está relacionada con el estado de baja escolaridad en los grupos sociales en situación de pobreza, la cual es transmitida y replicada a través de las generaciones durante largo tiempo, condenando a esta población a un círculo vicioso o una "trampa de pobreza" continua. Es de señalar que dentro de este grupo poblacional, otros estudios muestran que los no afro tienen una mayor movilidad social ascendente que los afro, teniendo estos últimos menores opciones y más obstáculos para conseguirla (Viáfara, et al., 2010).

En el caso de los hijos de migrantes afrodescendientes en Tuluá solo una de las personas entrevistadas no superó el nivel educativo de los padres, mientras el resto alcanzó el nivel de educación media o bachillerato completo y en algunas ocasiones niveles técnicos o tecnológicos, pero sólo dos de ellos han cursado, sin llegar a completarlo, el nivel de educación superior. Vale señalar que a pesar de haber superado el nivel de educación formal de los padres, y con esto percibir que se ha ascendido con respecto a los mismos, el logro efectivo para los entrevistados es mínimo o ninguno, cayendo en lo que se ha denominado la "trampa de la educación", pues todo el valor y la creencia dada a la educación como fórmula y herramienta para la movilidad ascendente resulta ser un espejismo o un logro que se percibe como insuficiente dada la necesidad de mayores niveles educativos para competir en el mercado. ${ }^{13} \mathrm{~A}$ esta idea se suma la percepción por parte de los informantes de unas persistentes condiciones de exclusión, marginación y discriminación racial:

Mi mayor expectativa era la de estudiar, y otras como conseguir un empleo. Formarme como profesionaly conseguirun buen empleo...perono, no se han dado las cosas (Estella, septiembre 22/2013)

13. El Departamento Nacional de Planeación (DNP) da cuenta de este mismo fenómeno, y lo extiende a toda la población afrodescendiente, en cuanto que "las mayores desigualdades educativas que enfrentan los individuos pertenecientes a hogares afrocolombianos sugieren que el sistema educativo no ha sido capaz de superar o por lo menos reducir las inmensas inequidades generadas en las instituciones presentes en las sociedades esclavistas. Un incremento en los años de educación no reduce las probabilidades de estar en una situación de indigencia o pobreza [...] para los afrocolombianos una alta inversión en capital escolar no garantiza mejorar sus condiciones de vida" (DNP, 2008: 33). 
Hay muy poquitas oportunidades para nosotros [afrodescendientes]. Pues como cuestiones de trabajo, como esperar uno más, muy poquito. Siempre en lo mismo... a lo sumo como vendedor (Jairo, octubre 04/2013)

La discriminación se ve, se ve marcada, si, todavía en las instituciones y en las dependencias donde se toman las decisiones, en los medios de comunicación y también con base en las oportunidades de empleo, porque todavía se tiene esa connotación de que los afrodescendientes, o bien sea comunidades indígenas, tienen que hacer los trabajos más pesados de la Nación (Estella, octubre $05 / 2013$ )

De otro lado, es necesario considerar que las condiciones socioculturales asociadas al consumo definen en buena medida hoy en día el estatus de las personas (Bauman, 2000), siendo cada vez más difícil para las nuevas generaciones de afrodescendientes mantenerse al margen de esta pauta de valor en relación con las prácticas de la sociedad en la que viven, donde las apariencias juegan un papel fundamental:

Es que la gente lo mira a uno de arriba a abajo. Hoy en día la gente lo mira de arriba a abajo a uno, si anda bien vestidoy anda mal vestido. Si anda mal vestido empiezan ay que yo no séqué, que yo no sé qué; o si no, pero mira fulanito anda bien vestido, buenas zapatillas, buen jean, buen busito, está entrando a "Quest" [Almacén de marca], está entrando a buenos almacenes y eso (Patricia, octubre 04/2013)

Uno quisiera hacerse a sus cosas, tener modito pa' darse sus gustos, que un buen reloj, una buena pinta o incluso comprarse un carro, o una moto aunque sea. Pero la gente lo ve a uno siempre igualito, siempre a piey con los mismos chiros [prendas] de siempre.(Hoover, agosto 13/2013)

Las expectativas de las personas jóvenes apuntan a lograr unos mayores niveles de consumo acorde con los imaginarios y los bienes puestos a disposición en el contexto social, los cuales resultan inalcanzables la mayoría de las veces. Si bien la adquisición de una vivienda se mantiene en este grupo de personas como una expectativa latente (todos los entrevistados menores de cuarenta años viven con los padres o en casa de los padres), ésta aspiración es enunciada marginalmente por los entrevistados y se percibe mucho menos accesible que la adquisición de otros bienes, los cuales son significativos en relación con los imaginarios de ascenso social de dichas personas, al tiempo que constituyen evidencia de ascenso social ante los otros.

Para las personas jóvenes entrevistadas resulta fundamental la evaluación que hacen los otros, el hecho de que la gente (la sociedad) observa, discrimina y valora a las personas a partir de los usos estéticos y de su capacidad de consumo, así como de las prácticas asociadas con éste. Para estos informantes la modestia en los consumos no se da por iniciativa propia o por una prevención moral, como sucede en muchos casos entre sus antecesores, sino por la imposibilidad material de realización de los consumos mismos. Esta privación genera sentimientos de inconformidad, 'vergüenza' 

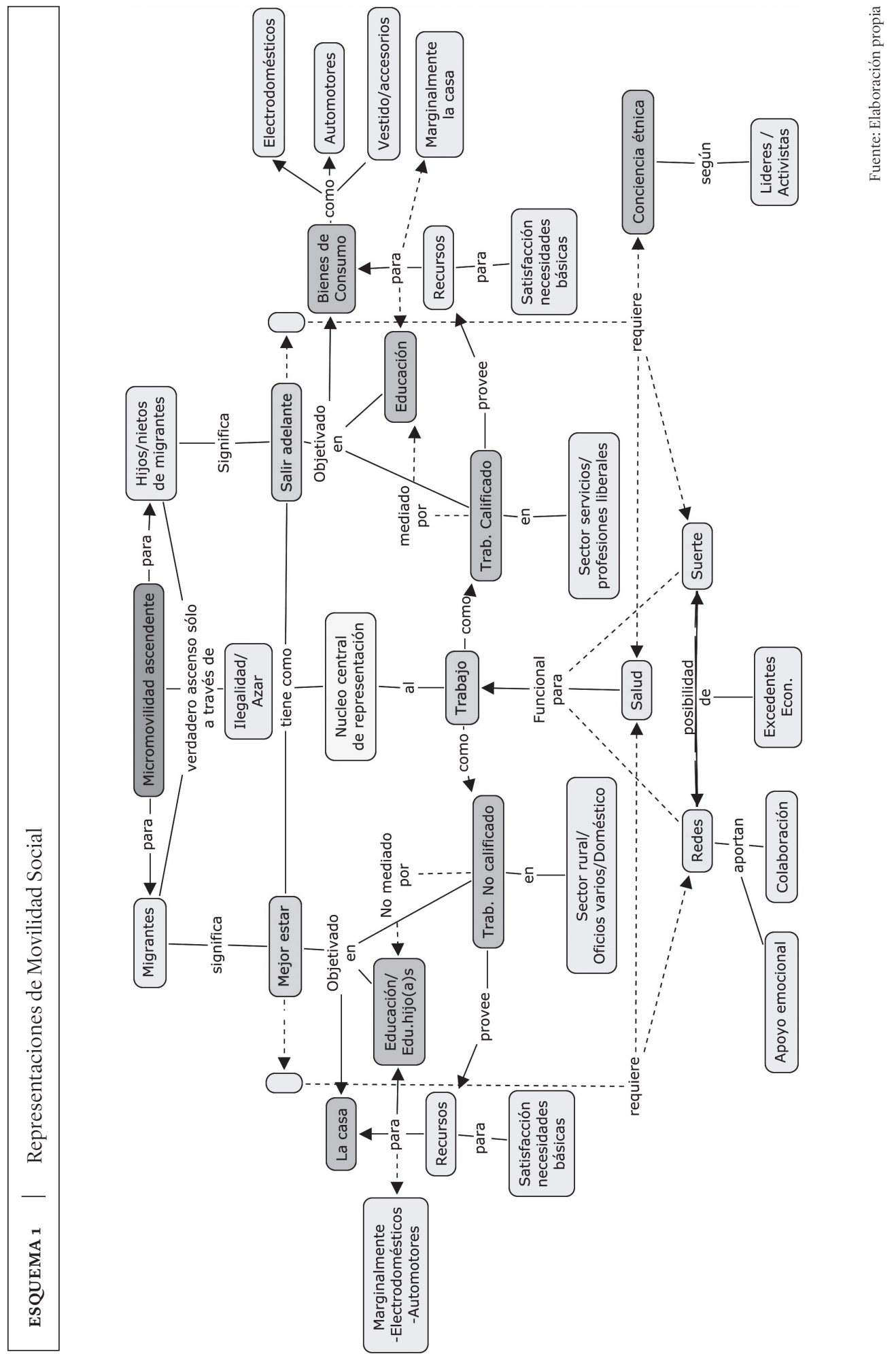
y reducción de la autoestima en la medida que es percibida como una incapacidad para disfrutar de los ofrecimientos del mercado, lo que genera la idea de no estar a la altura de los demás en cuanto a estándares de consumo, y por ende la percepción de un menor estatus social.

Las nuevas generaciones de personas afro entrevistadas tienen la ilusión y el deseo de: i) conquistar espacios sociales que históricamente les han sido vedados, principalmente en el sistema educativo y el mercado laboral; ii) contar con la suficiente autonomía sobre sus vidas y sus proyectos personales; iii) acceder a bienes y servicios socialmente disponibles en el contexto y iv) en el campo político constituir una identidad étnico racial que confronte y reclame para sí la igualdad de derechos y oportunidades (esto último para líderes comunitarios y activistas). Sin embargo, el no logro o el logro parcial de todas estas aspiraciones, configuradas en representaciones de ascenso social, constituyen la constante para las personas jóvenes o de mediana edad que colaboraron con el estudio.

Tanto para los migrantes como para sus descendientes el trabajo constituye la categoría central en la representación de movilidad social percibiéndose como medio y fin del ascenso mismo, sin embargo, en contraste con sus predecesores, para las nuevas generaciones el alcanzar un logro ocupacional está mediado por el logro educativo, el cual es percibido por los informantes como un prerrequisito para la consecusión de un empleo distinto al de sus padres. El estudio, la profesionalización y la subsiguiente consecución de un empleo bien remunerado que permita la adquisición de bienes y la satisfacción de necesidades, constituyen para esta población tanto el camino como la evidencia del salir adelante, como también el sustrato a partir del cual se elaboran las representaciones de movilidad, si bien éstas pocas veces llegan a concretarse.

La situación de lo(a)s hijo(a)s/nieto(a)s de migrantes se encuentra en la actualidad con un panorama laboral totalmente distinto al de sus antecesores: la tercerización, flexibilidad laboral y otras tantas tácticas del capital para eludir los derechos de los trabajadores, así como la cooptación de cooperativas y sindicatos por parte de los empresarios y la persistencia de las jerarquías y los imaginarios socioraciales constituyen obstáculos, en ocasiones insalvables, para la movilidad y ascenso social de este grupo poblacional. ${ }^{14}$

Una a una se repiten manifestaciones donde se vislumbra la insatisfacción por las aspiraciones no cumplidas o a medio cumplir, identificando el cerramiento del campo de oportunidades, articulado con la discriminación racial, como los mayores obstáculos para llevar a cabo las expectativas de ascenso social de las personas jóvenes afrodescendientes; expectativas creadas a partir de las promesas del propio contexto social en 
el que han crecido. Este cerramiento de oportunidades lo testifican todas las personas entrevistadas, pero son las más jóvenes quienes lo visualizan como producto en buena medida del orden racial de la sociedad tulueña, donde el racismo y la desigualdad fungen de árbitros para la movilidad social'15:

Para una persona negra ascender se le debe dar la oportunidad a que trabaje, que se eduque y que tenga los mismos derechos, las mismas oportunidades que tienen las personas blancas (Jairo, octubre 04/2013)

Y si usted es un blanco y somos dos, y él es blanco y usted es negro, obvio el blanco se va a llevar más el trabajo que nosotros, asi no tenga muchos estudios, asi seamos nosotros superiores al otro (Gina, octubre $04 / 2 \mathrm{O} 13$ )

La conciencia étnica, entendida como el reconocimiento y la toma de posición frente a las asimetrías y las desigualdades sociales históricamente producidas a partir de la diferencia etnoracial, no constituye un rasgo extendido y generalizado en la población afrodescendiente entrevistada. Para algunas personas, principalmente los jóvenes en el campo cultural y los líderes cívicos en el ámbito político, el salir adelante incluye el desarrollar una conciencia étnica colectiva y el reconocimiento de la población afro como sujeto político, que reclame para sí la igualdad de derechos así como la discriminación positiva en las políticas estatales.

Por último, aunque no menos importante, para el conjunto de los informantes la salud, el azar, la suerte y las redes familiares y sociales configuran caminos y potencialidades para la movilidad, aunque por cuestiones de espacio no se desarrollan en este artículo. El ganarse un juego de chance, la lotería u obtener o no por cosas del destino un buen empleo son cuestiones que caben, y no marginalmente, en el imaginario de las personas como posibilidades de ascenso social, así como el contar con un grupo familiar solidario y cooperativo y algunas relaciones sociales que sirvan de 'palancas' para la consecución de un puesto de trabajo resultan esenciales a la hora de pensar en unas mejores condiciones de vida.

\section{Conclusiones}

En términos generales, el ascenso social (mejor estar, mejor vida) es percibido por los informantes como un proceso vinculado con el paso de unas difíciles condiciones de vida a unas mejor valoradas, objetivadas éstas diferencialmente de acuerdo con logros

15. Para el caso de Bogotá: "cuando se controla por variables asociadas con la posibilidad de conseguir empleo, se concluye que tener fenotipo afrodescendiente disminuye de manera significativa las probabilidades de conseguir una entrevista de trabajo, mientras que tener un fenotipo blanco las aumenta considerablemente" (Rodríguez, et al., 2013: 22) 
sociales, culturales y económicos propios de los contextos sociohistóricos en los que crecieron y se insertaron, tanto los migrantes como sus descendientes (Pacífico-rural a Tuluá-urbano).

En los territorios del Pacífico un "mejor estar" empieza a requerir, entre otras cosas, de una mayor cantidad de recursos económicos, representados en dinero. El estudio muestra que las personas migrantes entrevistadas aspiraban con su desplazamiento a una vida con menos dificultades económicas, buscando satisfacer sus necesidades básicas y cumplir posteriormente con aspiraciones ligadas a logros sociales y culturales. La incorporación a los nuevos contextos sociales, no obstante representar para algunos migrantes unas mejores condiciones económicas a las anteriormente vividas, se materializó ubicándolos en los últimos peldaños en la escala ocupacional y de prestigio.

De otro lado, el acervo cultural y las competencias de los migrantes en las labores del campo adquiridas en los lugares de origen, así como los condicionamientos de la estructura social y ocupacional racializada del contexto de llegada, constituyen el marco a la dinámica, el sentido y la significación de la movilidad y el ascenso social para estas personas migrantes afrodescendientes, restringuiendo dicha movilidad a un estrecho margen en los tipos de oportunidades (aunque amplias en oferta laboral), las cuales coadyuvan a definir las posibilidades reales y las representaciones de lo que constituye ascender socialmente. De tal forma, el significado de ascenso social que elabora la población migrante entrevistada parte de lo que podría llamarse una micromovilidad social.

Respecto a la movilidad social es necesario señalar que, aun bajo condiciones de explotación y discriminación racial, se presenta una micromovilidad ascendente en la mayor parte de hombres migrantes y sus familias, debido principalmente a: 1) el esfuerzo personal y familiar; 2) la implementación de una lógica prospectiva; 3) las condiciones de contratación directa con los mínimos derechos y prestaciones sociales (principalmente en los ingenios) y 4) la unión y la potencia solidaria de los sindicatos y las cooperativas.

De manera sintética podemos decir que las nuevas generaciones de afrodescendientes, nacidos y/o criados en Tuluá, consideran la movilidad social a partir de:i) conquistar espacios sociales que históricamente les han sido vedados, principalmente en el sistema educativo y el mercado laboral; ii) contar con la suficiente autonomía sobre sus vidas y sus proyectos personales; iii) acceder a bienes y servicios socialmente disponibles en el contexto, y iv) en el campo político constituir una identidad étnico racial que confronte y reclame para sí la igualdad de derechos y oportunidades. La mayor parte de estas expectativas no se cumplen o se cumplen parcialmente para los entrevistados de estos grupos generacionales, generando percepciones de inmovilidad o descenso social.

Vale decir que tanto para los migrantes como para las nuevas generaciones el trabajo constituye la categoría central en la representación de movilidad social, percibiéndose como medio y fin del ascenso mismo, sin embargo, en contraste con sus predecesores, 
para las nuevas generaciones el alcanzar un logro ocupacional está mediado por el logro educativo, el cual es percibido por los informantes como un prerequisito para la consecusión de un empleo distinto al de sus padres.

Si bien los informantes conciben una estructura laboral racialmente discriminada, se nota en ellos la necesidad de resistirse a aceptar las condiciones y ámbitos del empleo impuestos históricamente a la población afrodescendiente. En los motivos de esta resistencia entran en juego las condiciones objetivas de transformación del mercado laboral; la inversión en la jerarquía de valores y expectativas referidas a la movilidad y el ascenso social de las nuevas generaciones de afrodescendientes, así como la resignificación de lo "negro" en la sociedad actual, el consecuente proceso de etnización de las comunidades afro y la incorporación legal de sus derechos a partir de la constitución de 1991 y la ley 70 del 93, las cuales sirven de base para la interlocución de dicha población con la sociedad civil y el Estado en el marco del discurso de la multiculturalidad.

Los deseos, las intenciones a futuro y los proyectos de vida de las personas jóvenes involucran la idea de la elección autónoma de un oficio u ocupación por fuera de los marcos sociales e históricos asignados a las personas afro. No obstante, en todas las declaraciones la condición socioeconómica se percibe como un obstáculo difícil de sortear para tal aspiración en toma decisiones autónomas con respecto a su futuro ocupacional. Los hombres y mujeres jóvenes parecen saber lo que quieren o anhelan en cuanto a desempeño en su actividad social productiva, pero tales aspiraciones no son vistas la mayoría de las veces como una posibilidad real sino que están sujetas a un marco de oportunidades que se percibe estrecho y condicionado, lo cual llena el futuro de incertidumbre. Para lo(a)s jóvenes, lo(a)s cuales aspiran al ascenso social a partir de unos mayores niveles educativos y de una movilidad horizontal, un cambio cualitativo en la actividad laboral, siempre cabe la posibilidad de verse obligados a desempeñarse en oficios no deseados o considerados por ellos de menor estatus, viéndose impelidos a reproducir el círculo de exclusión y marginación social.

\section{Referencias}

ABRIC, J. C. (2001) Prácticas sociales y representaciones. Edic. Coayacán, México.

BARBARY, O. Y URREA, F. (Eds.). (2004). Gente negra en Colombia. Dinámicas sociopoliticas en Caliy el Pacífico. Edit. Lealon, Universidad del Valle - IRD - Colciencias, Medellín.

BAUMAN, Z. (200o) Trabajo, consumismo y nuevos pobres. Edit. Gedisa, España.

BOURDIEU, P. (1990) Sociología y Cultura. Edit. Grijalbo, México.

BRAVO, C; ESCOBAR, C; RIVERA, L. (2002) Estudios afrocolombianos y educación intercultural. 
Nación y región. Edit. Papiro, Colombia.

CIFUENTES, A. (Comp) (1986) La participacion del negro en la formación de las sociedades latinoamericanas. Centro de estudios Franz Fanon / ICAN, Bogotá.

DEPARTAMENTO NACIONAL DE PLANEACIÓN (2008). “Insumos para el análisis de las barreras que impiden el avance de la población negra, afrocolombiana, palenquera y raizal”. Documento de trabajo, Bogotá.

DIENER, E. (1994) “El bienestar subjetivo”. Revista Intervención Psicosocial. Vol 3 No 8.

ELSTER, J. (1996) Tuercasy tornillos. Una introducción a los conceptos básicos de las ciencias sociales. Edit. Gedisa, España

FRANCO, R.; LEÓN, A. Y ATRIA, R. (Coord.) (2007). Estratificación y movilidad social en América Latina: transformaciones estructurales en un cuarto de siglo. Naciones Unidas, CEPAL, Chile.

GRILLO, S.; NINA, E. (2000) “Educación, movilidad social y “trampa de pobreza”". Revista Coyuntura Social No 22, Bogotá.

HURTADO, T. (1996) Las migraciones 'norteñas' y el impacto sociocultural sobre la población urbana de Buenaventura. Cidse, Univalle, Cali.

JARAMILLO, J. (2003). Los migrantes del Pacifico en Cali: Trayectorias biográficas y sentidos territoriales. Unidad Central del Valle del Cauca, Centro de investigaciones y publicaciones, Tuluá.

KNIGHT, R. (1986) "La respuesta de la industria azucarera a la sindicalización en el sector”. Boletín socioeconómico Cidse, Univalle, Cali.

PISANO, P. (2014) “Movilidad social e identidad "negra" en la segunda mitad del siglo xx". Anuario Colombiano de Historia Social y de la Cultura, Vol. 41 No 1, Bogotá, pp. 179-199

RODRÍGUEZ, C.; ALFONSO, T. Y CAVELIER, I. (2008) El derecho a no ser discriminado. Primer informe sobre discriminación racialy derechos de la población afrocolombiana. Observatorio de discriminación racial, Bogotá.

RODRÍGUEZ, T.; GARCÍA, M. (coordinadoras) (2007) Representaciones sociales. Teoría e investigación. Universidad de Guadalajara, México.

TAUSSING, M. (1979). Destruccióny resistencia campesina 1970-1978. Edit. Punta de Lanza, Bogotá.

URREA, F. (2011) “La conformación paulatina de clases medias negras en Cali y Bogotá a lo largo del siglo XX y la primera década del XXI”. Revista de Estudios Sociales No 39, Bogotá, pp. 24-41.

URREA, F. (2010) "Patrones sociodemográficos de la región sur del Valle y Norte del Cauca, a través de la dimensión étnica-racial”. En Castillo, et al. Etnicidad, acción colectiva y resistencia. Universidad del Valle, Cali, Colombia.

URREA, F.; ARBOLEDA, S.; ARIAS, J. (2000) Construcción de redes familiares entre migrantes de la 
costa pacificay sus descendientes en Cali. Universidad del Valle, Proyecto Cidse-Ird, Documento de trabajo No 48 , Cali.

URREA, F.; MURILLO, F. (1999) “Dinámicas de poblamiento y algunas características de los asentamientos populares con población afrocolombiana en el oriente de Cali”. En Desplazados, migraciones internas y reestructuraciones territoriales, Centro de estudios sociales-CES, Universidad Nacional de Colombia, Bogotá, pp. 337-405.

VANÍN, A. (1998). "Alianzas y simbolismos en las rutas de los ausentes y los retornantes". Documento de trabajo. Cidse $\mathrm{No}_{16} 6$, proyecto Cidse-IRD, Univalle, Cali.

VEENHOVEN, R. (1994). “El estudio de la satisfacción con la vida”. Revista Intervención Psicosocial, Vol. 3 No 9.

VEBLEN, T. (1974) Teoría de la clase ociosa. Fondo de Cultura Económica, México.

VIÁFARA, C.; ESTACIO, A.; GONZÁLEZ, L. (2010). “Condición étnico-racial y movilidad social en Bogotá, Caliy el agregado de las trece áreas metropolitanas en Colombia: un análisis descriptivo y econométrico". Revista Sociedad y Economía No 18, Universidad del Valle, Cali, Colombia.

VIÁFARA, C. (2006). "Efectos de la raza y el sexo en el logro educativo y el estatus ocupacional en el primer empleo en Cali-Colombia”. Revista Sociedad y Economía No 11, pp. 66-95

WADE, P. (1997). Gente negra nación mestiza. Dinámicas de las identidades raciales en Colombia. Edit. Andes, Medellín, Colombia.

ZULUAGA, J.C. (200o) “Oralidad y género: relatos del Valle - Chocó”. Universidad del Valle. Tesis de grado en Sociología, Cali, Colombia. 